\title{
Exploration on the Career Development of Ecology Tourism Economy Hotel Core Staff
}

\author{
Niu Wentao, Zhang Chunguo \\ Institute of Economics \& Management \\ Sichuan University of Science and Engineering \\ Sichuan Zigong 643000 China
}

\author{
Gao Ju \\ College of Life Science \& Science \\ Sichuan Agricultural University \\ Sichuan,China
}

\begin{abstract}
The core employee of the hotel is the key factor affecting the survival and development of ecological tourism and the economic hotel. Therefore, the research of core employees' career development about the economic hotel is particular important. This article through questionnaires, carry out on-site interview to the core employees of ecological tourism economic hotel, the resulting data were analyzed by North Forest software, come to the conclusion that core employees exist issues such as poor coordination and single career development paths, and propose the approach and method that optimize career development of economic hotel core employee .
\end{abstract}

Keywords-ecological tourism, economic hotel, core employees, career development

\section{INTRODUCTION}

Eco-tourism is based on the principle of sustainable development, a new travel way of focusing on a return to nature; it emphasizes the protection of ecological resources, but without losing the essential attribute of tourism: economy. Eco-tourism economy is coincide with economic development's speed, And its emphasis on sustainable development is consistent with the quality of economic development, it become a new economic growth point of tourist industry in just a decade is not surprising. Driven by the eco-tourism that emphasis on natural conservation,

Economy hotels are prosperity. Economy hotels often lead to the decline quality of service while favorable; customers began to think that the economy is not economical. Core staff plays a key role in the economy hotel, therefore, the research to the career development of ecology hotel core staff is extremely important for enhancing the competitiveness of the whole economy hotels.

This article is based ecology tourism, from the perspective of career management, explore the importance of economy hotel core staff, select ecology tourism economy hotels questionnaire, obtain relevant data, conduct research and analysis on the data, find the problems of economy hotel core staff, propose feasibility proposal to problems.

\section{DEFINE THE ECOLOGY TOURISM ECONOMY HOTELS} CORE STAFF

Core staff with key knowledge or technology in the enterprise; occupy key positions which relation lifeblood of business survival; affect the future strategic development, they have an irreplaceable role, once the loss directly affect the normal operation of enterprises, create value for the enterprise which goes far beyond the value of their own. [1]I personally investigation into the relevant economy hotel, make the most typical internal structure, at the same time, the staff who in the key positions were studied, ecology tourism economy hotels core staff were carried out a detailed classification and summary, its core staff, including the managers of the three main sectors, especially kitchen managers and lobby managers, the food and beverage industry most rely heavily on service and dishes, it is not difficult to know, lobby and kitchen managers are the core staff. In addition, the service director and executive chef of seafood should also be attributed to the core staff, waiter is most difficult to manage, and service supervisor should belong to the core staff of management; As we all know, seafood is the best embodiment dish of chef level, chef in charge of seafood should belong to core staff who grasp the professional and technical skills. Ecology tourism economy hotel core management staff should naturally grabbed by two levels which are management and technology.

\section{THE IMPORTANT SIGNIFICANCE OF THE CORE} ECONOMIC HOTEL STAFF CAREER DEVELOPMENT

Ecology tourism as a new driving force for driving economic development, its potential has not been fully played out, this will inevitably bring further heating ecology tourism, as a service-based tertiary industry, economic hotel's development is crucial. seize key staff's career development management, not only for their own development, lay the human foundation for corporate longterm planning, but for the entire ecology tourism industry, will have an invaluable role even to the long-term development of the entire national economy [3]

Carry out career management to the economic hotel core staff, it is bound to take appropriate training programs to the core staff, thus enhancing the overall quality of individual ability and economy hotels of core staff. Provided preferential welfare treatment for the core staff, and other development, will improve satisfaction and pleasure of core staff, thereby increasing their loyalty, in turn enhance the value of hotel's human capital, core staff's satisfaction be improved will influence customer satisfaction's increase, and enhance the core competitiveness of economy hotels. [4]Economy hotels focus on the core staff 's career 
development, will have a positive effect to promote the general staff 's work effort extent, reduce the hotel's interior complain, the hotel and staff will achieve win-win.

\section{THE PROBLEMS OF ECOLOGY TOURISM ECONOMY HOTEL CORE STAFF IN CAREER DEVELOPMENT}

\section{A. Lack of core staff in key sectors}

In economic hotel, lobby, kitchen and finance departments separate to complete their tasks, resulting in many work that need to coordinate with each other can not be completed quality and quantity, for example, there is a conflict in delivering dishes ministry under the jurisdiction of the lobby because of guests' reminder vegetables, and the purchasing department managed by financial sector, kitchen every needs to report the number of dish's materials everyday, to facilitate purchase. All of these problems arise is because economy hotel too much emphasis on savings, not set up the relevant coordinate departments. Also public relations department that need to communicate are not common at economic hotels, lack communication between the company's public relations department and tourism company, the situation will be bad. Lack of internal coordination and external public relations department with a lack of communication management skills of core staff has become a stumbling block on the development of economy hotels.

\section{B. Core staff has poor coordination between living and working}

In economic hotel, the turnover of core staff in finance department rate close to zero, core staff in cooks sector master key techniques, their wages are higher compared to other sectors, opportunities for off-duty is greater, although their work environment is not very good, but the advantages of pay and benefits are far inferior than working environment, core kitchen's turnover rate is also low. and relative to these two sectors, core staff in lobby has a high turnover rate, reason for leaving is because of much conflict exist in life and work, on the other hand, the core staff of lobby almost are women, they care more about their working hours and family issues, this leads to lower satisfaction, loyalty to the hotel decline.

\section{Core staff career development mechanism backward}

Economy hotel core staff career development mechanism is still in its infancy, first of all, aspects of incentives, from the lateral view, the hotel does not pay the balance achieved between the various departments, vertical view, the hotel did not pull the core staff and general staff the pay gap.[6]Secondly, the training development mechanism, economic hotel is simply give vocational training to general staff, just their experience for training, absolutely no special training to the core staff. Again, although the career path to achieve a two-track career path technology and management, but only to stay in form. Finally, the evaluation criteria in the core staff, the hotel is just to measure the success of core staff through salary, bonuses, benefits or not, do not pay attention to change from the internal reward to outside reward, which is the reason that high turn over rate of core staff in economic hotel.

\section{Core staff has cognitive bias to career development}

Economic hotels uneconomic is because customers consider cost is not low, hotels are economic is in terms of core staff, economic hotels can save money on the province, because the boss consider as long as they can save money is earned money. So human resources department in this hotel is simply personnel secretary, the core staff career development is in question.

The hotel core staff although very much hope plan their career development, but because variety of work pressure, lack of professional skills, coupled with a slight fluctuation in the performance, loyalty of core staff on a sharp decline, eventually lead to the loss of core staff.

\section{APPROACHES AND METHODS THAT OPTIMIZE CORE STAFF PROFESSIONAL DEVELOPMENT}

\section{A. Establish match fit mechanism between core staff and for key sectors}

Pareto efficiency rules think companies' benefit by $80 \%$ to $20 \%$ of employees to create, and that $20 \%$ of staff is the company's core staff, as far as I understand, the core staff of this economic hotel is far less than $20 \%$, able to $10 \%$ is quite good, in order to create more efficiency, increase the proportion of the percentage of core staff is the key.

As the core of the human resources department, while building exterior horizontal communication departments and public relations departments within the hotel, so that internal and external integration, develop core staff who has a variety of skills, While taking internal promotion and external recruitment, and actively explore the inner core staff with a variety of talents and attract external talent person with extensive management experience and strong technical skills.[7]Through internal evaluation, based on the unique strengths of these core staff, assigned them to key sectors which need such expertise, achieve a high degree of fit with the core technical skills of its own staff in key sectors, to achieve a win-win..

Chart: 4-1 The chart that economic hotel core staff career development match with key sectors

\section{B. Take time record card and flexible work system}

We can determine the measure of time as to enhance the fairness of among staff, in a two-week settlement period, to require regular daily working hours as the standard, exceeding the prescribed time is overtime. Record per core staff two weeks of overtime on the card, according to their needs, they can put the time that recording on the card into salaries, but also can be exchanged for off-day, achieve a balance between work time and life.

Secondly, change the existing system of hard work into flexible work system, core staff can take shifts with colleagues to solve the problem of insufficient time. When the tourist season coming, the hotel can increase the number of staff by hiring temporary employee, reduce work-life Conflict, but they must ensure the quality of hotel services. 


\section{Improve core staff career management mechanism}

From the traditional career to change without borders career management is from a single enterprise selfmanagement core staff professional development to transform business and individuals to participate in professional development, which requires companies no longer use a rigid system of management core staff and people, and return to the management of the core intentions of management. [8]

Establish a human resource department led and the department manager for the assistance, managers at all levels of the core staff directly responsible for career management mechanism; improve information consultation mechanism of core staff career development, improve core staff's feedback capability to career development. In this way, the hotel can maintain internal quality, improve service value, and thus improve customer satisfaction, customer loyalty, making the hotel substantial increase profitability and ensure long-term development of the hotel.

\section{To corporate culture and values as the basis to strengthen the core staff professional awareness}

Companies with ambitious future development must be their hard power and soft power combination, only through hard power without soft power to support, companies will obviously fell inadequate stamina. Through the economic hotel core staff on the corporate culture and core values satisfaction survey, we can found that the hotel core staffs still hold a positive attitude. The hotel is entirely possible to culture and values as a breakthrough, correct core staff cognitive biases. [9]

First, strengthen the core staff to learn their own cultural characteristics. Secondly, through the cultural propaganda window, set the typical role models of core staff, motivate subordinates to work hard. Again, the hotel can demonstrate hotel features cultural activities to strengthen cohesion and teamwork of all employees.

\section{REFERENCES}

[1] Robert H.Wateman. Finding and Keeping the Best People. [M].China Renmin University Press. 2003:56

[2] HU Zhenhao. Conduct Career Planning and Implement Human Resource Management [J].Shanghai Business. 2003.9:23

[3] MENG Ni. Sustainable Development of the Hotel Industry Needs over Talent Hurdle [N]. International Business Daily.

[4] JIANG Yi, LUO Xingtao, LU Xianwang. Research on Human Resource Management of Economic Hotels[J].Market Forum. 2008(01):47

[5] GONG Zilan. Research on Career Satisfaction of Hotel Staff in Economic Chain[J].Enterprise Herald. 2013(01):205-207

[6] LIAO Tao, ZHANG Xuemei. Analyze to Compensation Management of Economic Hotels in Chengdu [J]. Economic Research Guide. 2013(02) : 69-72

[7] BAi Yanli. Career Management Career in the Era of Borderless [J].China Human Resources Development.2007.4:22-24

[8] ZOU Zhong. Cultural Fit Based Management of Improper Behaviors Beyond the Scope of Regulations [J].Business economy. 2013(03):84-86

[9] TONG Jing, JIANG Hairzhen. How to Train and Keep on Hotel Key Employees-Based on the Viewpoint of Human Resource Management[J].Journal of Qingdao Hotel Management College. 2010(04):17-19 